\title{
Maternal and Foetal outcome in Cholestasis of Pregnancy
}

\author{
Sinha $\mathrm{K}^{1}$, Pandey $\mathrm{S}^{2}$, Das $\mathrm{CR}^{3}$
}

\begin{abstract}
Background: Obstetric cholestasis has been associated with an increased risk of preterm delivery, intrapartum meconium, foetal distress and intrauterine foetal death. Objectives: To know the perinatal outcome of cholestasis in pregnancy. Materials \& Methods: This is a hospital based Observational study conducted in the department of Obstetrics \& Gynaecology at Nepalgunj Medical College Teaching Hospital Kohalpur between August 2015 to January 2016. A total of 40 patients were included in the study with diagnosis of obstetric cholestasis. Data were recorded \& analysed. Results: The study group of 40 mothers delivered 40 new born. Mean age group of women in the study was $24.9 \pm 5.5$ years $\& 70 \%$ were primigravida. The mean gestational age at onset of pruritus was $30.33 \pm 4.24$ weeks. The rate of caesarean section was $40 \%$. Premature membrane rupture noted in $20 \%$ cases while $17.5 \%$ were postpartum haemorrhage. Regarding foetal outcome; meconium baby $32.5 \%$, Intrapartum foetal distress $17.5 \%$, preterm baby $10 \%$ while $37.5 \%$ were complication free. There was $2.5 \%$ of intrauterine foetal death, where pregnancy continued beyond 38 weeks. Thirteen new borns (32.5\%) were admitted to neonatal intensive care unit. Conclusion: Cholestasis in pregnancy is high risk group with adverse perinatal outcomes.
\end{abstract}

Key words: cholestasis, perinatal

\section{INTRODUCTION}

Intrahepatic cholestasis of pregnancy (ICP) is defined as pruritus with onset in pregnancy which is associated with abnormal liver function in the absence of other liver diseases which resolves following delivery. ${ }^{1}$ ICP develops during second half to third trimester of pregnancy. In the first description of ICP in 1883, Ahlfield described maternal pruritus and jaundice in the last trimester of pregnancy disappearing after delivery. ${ }^{2}$ A low incidence of $0.2 \%$ in Europe and a high incidence of 4$14 \%$ in Chile have been reported. ${ }^{3}$ ICP affects $1.2-1.5 \%$ women of Indian Asian and Pakistani Asian origin. ${ }^{4}$ One study has suggested that it is more common in women over the age of 35 years. A higher incidence is seen in twin pregnancies $(20-22 \%)^{5,6}$

The most common presenting symptom is pruritus that usually presents in the third trimester, becomes progressively more severe as the pregnancy advances and typically resolves within 48 hours of delivery. Approximately $80 \%$ of affected women present after 30 weeks of gestation, ${ }^{7,12}$ but ICP has been reported as early as 8 weeks ${ }^{13}$.It has been reported that itch may be present either prior to or after abnormal liver function is detected, ${ }^{14}$ Clinical jaundice is rare, affecting approximately

\footnotetext{
1. Dr. Kavita Sinha

2. Dr. Subhash Pandey

3. Prof. C. R. Das
}

\section{Address for correspondence:}

Dr. Kavita Sinha

Department of Obst. \& Gynae.

Nepalgunj Medical College \& Teaching Hospital

Kohalpur, Banke, Nepal

Email: samesome2002@yahoo.com
$10-15 \%$ of pregnant women with ICP and the biochemical abnormalities resolve within 2-8 weeks of delivery ${ }^{2}$.

Uterine and Placental consequences-A significant increase in uterine contractility has been shown during the course of the disease, an event that has been related to the high incidence of spontaneous preterm labour. Perinatal consequences-Higher incidences of clinical markers of intrauterine asphyxia, such as meconium staining of amniotic fluid and foetal disress ${ }^{11,5}$ have been described. There is association between ICP and Preterm labour ${ }^{11,5,15-7}$ The reported frequency of ICP related still birth is as high as $35 \%$ which is double that of normal population ${ }^{11}$. A higher incidence of unexplained $3^{\text {rd }}$ trimester foetal death has been described in association with severe ICP. The foetus shows no evidence of growth restriction and has normal surveillance tests 1 week or less before the foetal death ${ }^{18}$.

Recent studies suggest that oral use of Ursodeoxycholic acid improves maternal clinical and biochemical features and may prevent the foetal effects of $\mathrm{ICP}^{19-24}$. Careful foetal assessment and appropriate medical intervention have improved the perinatal outcome ${ }^{5}$. Labour is induced unless contraindicated, at 38 weeks of gestation, In patients with jaundice the induction will be planned from 36 weeks onwards, after evaluation of lung maturity by amniotic fluid and amniotic fluid analysis ${ }^{8}$. As the incidence of Cholestasis of pregnancy in southeast Asia is 1.2-1.5\% and as it has adverse maternal and perinatal consequences, so this study has been conducted.

\section{MATERIAL AND METHODS}

Hospital based Observational study was conducted from August 2015 to January 2016 at Nepalgunj Medical College Teaching Hospital, Kohalpur, Banke, Nepal. Forty women with 
Obstetric Cholestasis were included in the study. The pregnant lady, both primigravida and multigravida, may or may not be in labour, with Cholestasis of Pregnancy were included while Viral Hepatitis (A, B, C and E), Gallstone Diseases \& Preexisting Liver Disease, IV Drug abuse, Alcohol abuse, other concomitant drug use such as Methyldopa were excluded from the study. A detailed history and clinical evaluation was done. Written informed consent was taken.

All the patients were subjected to routine ANC investigations, ultrasonogram for foetal assessment and Biophysical profile of foetus, maternal scan to rule out gall stone diseases, serology to rule out Hepatitis A, B, C, E and liver function Tests. Patients were admitted in the hospital depending upon the severity of symptoms, state of liver and period of gestation at the time of presentation.

Babies were evaluated for features of prematurity, weight, meconium aspiration at birth and for any other complications.

\section{RESULT}

Table I shows age distribution of subjects. Maximum number of subjects belong to age group of $18-35$ years (87.5\%). Table II shows number of subjects having onset of pruritis belong to 32-36 weeks of gestation constituting 40\%. Table III shows Complications of Pregnancy with obstetric cholestasis, 12 subjects constituting complications like emergency caesarean section. Figure I shows Foetal outcome. 37.5\% having no complications. Amniotic fluid meconium was next common

\begin{tabular}{|c|c|c|}
\hline Age in years & Number $(\mathbf{n}=\mathbf{4 0})$ & Percentage \\
\hline$<18 y r s$ & 4 & 10 \\
\hline $18-35 y r s$ & 35 & 87.5 \\
\hline$>35 y r s$ & 1 & 2.5 \\
\hline Total & 40 & 100 \\
\hline
\end{tabular}

Table I: Age distribution

\begin{tabular}{|c|c|c|}
\hline $\begin{array}{c}\text { Weeks of gestation } \\
\text { at onset of } \\
\text { pruritus }\end{array}$ & Number $(\mathbf{n = 4 0 )}$ & Percentage \\
\hline$>36$ & 2 & 5 \\
\hline$<24$ & 4 & 10 \\
\hline $24-28$ & 7 & 17.5 \\
\hline $28-32$ & 11 & 27.5 \\
\hline $32-36$ & 16 & 40 \\
\hline Total & 40 & 100 \\
\hline
\end{tabular}

Table II: Gestational age at onset of pruritus complication of pregnancy. Figure 2 shows Neonatal intensive care unit admission. Neonatal sepsis (54\%) was most common cause to be admitted in NICU.

\begin{tabular}{|l|c|c|}
\hline Complications of Pregnancy & Number $(\mathbf{n = 4 0 )}$ & Percentage \\
\hline $\begin{array}{l}\text { Premature rupture of } \\
\text { membrane }\end{array}$ & 6 & 15 \\
\hline $\begin{array}{l}\text { Prelabour premature rupture } \\
\text { of membrane }\end{array}$ & 2 & 5 \\
\hline $\begin{array}{l}\text { Spontaneous Preterm } \\
\text { Delivery }\end{array}$ & 4 & 10 \\
\hline Oligohydramnios & 5 & 12.5 \\
\hline Elective Caesarean section & 4 & 10 \\
\hline Emergency caesarean section & 12 & 30 \\
\hline Postpartum haemorrhage & 7 & 17.5 \\
\hline
\end{tabular}

Table III: Complications of Pregnancy with obstetric cholestasis

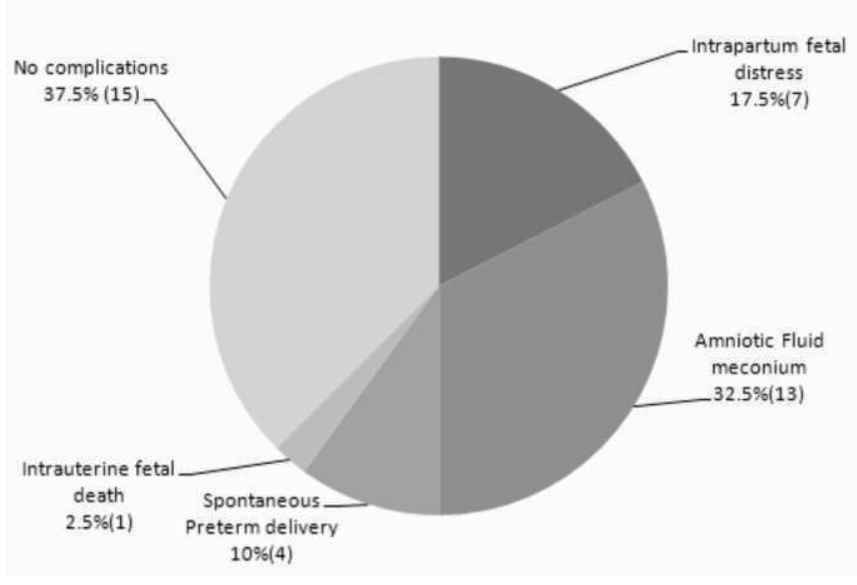

Figure 1: Foetal outcome

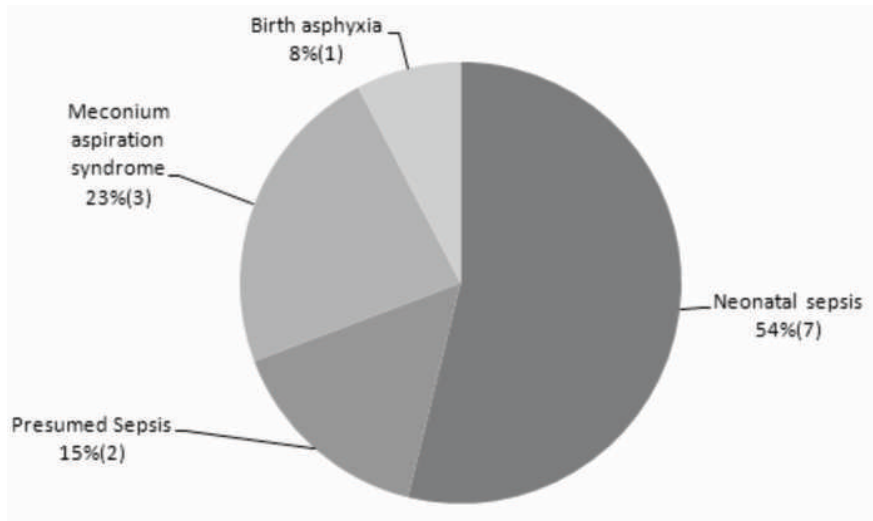

Figure 2: Neonatal intensive care unit admission 


\section{DISCUSSION}

Intrahepatic cholestasis of pregnancy (ICP) or jaundice in pregnancy is usually observed in third trimester. The usual symptom is pruritus and deranged liver function test. This condition has adverse effect in the delivery, causing maternal and foetal morbidity \& mortality.

The majority of patients in our study underwent lower segment cesarean section which was $40 \%(16)$. Out of 16 cases, $25 \%(4)$ underwent Elective caesarean section while $75 \%(12)$ underwent emergency caesarean section. According to Turunen et al (2010), the incidence of Cesarean section was found to be $14.8 \%{ }^{25}$ which is very low, as most of the women in this study were induced and delivered vaginally. Similarly the study conducted by Padmaja et al (2010) and Wang et al(2006), the incidence of Cesarean section was found to be $93.3 \%$ and $85.9 \%{ }^{26}$, respectively which is very high, attributed to high incidence of complicated pregnancies in their hospital

Alokanada et al in 2005 found that the incidence of post partum hemorrhage was $25 \%(8 / 32)^{3}$, which somehow correlates our study as $17.5 \%,(7 / 40)$ while Wang et al(2010) the incidence of post partum haemorrhage in their study was only $1.4 \%{ }^{26}$.

In our study, Prelabour rupture of membranes (PROM) was found in 15\%(6/40) and Premature prelabour rupture of membranes (PPROM) was seen in $5 \%(2 / 40)$ of cases. According to Padmaja et al where the incidence of Premature Prelabour rupture of membranes was observed to be in $8.9 \%$ of cases $^{9}$ as most of the women were delivered before 37 weeks of gestation (either spontaneous or latrogenic) in this study.

Regarding the preterm delivery the incidence was $10 \%(4 / 40)$, which was similar to Sultana et al (2009) study, having the incidence of spontaneous preterm delivery as $10 \%{ }^{4}$.Wang et al(2006), the incidence of Preterm delivery was found to be $24 \%{ }^{26}$ whereas In Rioseco et al(1994), the incidence was $12.1 \%{ }^{5}$, higher than ours.

We have found that the incidence of meconium staining of amniotic fluid in women with Obstetric cholestasis as $32.5 \%(13 / 40)$.It was similar to Mei-ting et al (2014) study, where the incidence of meconium stained liquor was found to be $33.3 \% .{ }^{10}$ Similarly Sultana et al(2009) observed the incidence of $20 \%(6 / 30)^{4}$ in their subjects and Wang et al (2006), found the incidence of meconium stained liquor to be $23.2 \%{ }^{26}$.

The incidence of Intrapartum fetal distress in women with Obstetric cholestasis was found to be $17.5 \%$. According to Padmaja et al, Intrapartum fetal distress seen in $4.4 \%{ }^{9}$ women with obstetrics cholestasis which is low attributed to proper ANC visits and timely treatment of obstetrics cholestasis. Rioseco et al, incidence of intrapartum. Fetal distress was found to be $12 \%$ which is low attributed to proper ANC visits and proper treatment of cholestatsis ${ }^{5}$.
Intrauterine Fetal Death was found to be $2.5 \%$. According to Sultana et al (2009), the incidence of IUFD was found to be $6.67 \%{ }^{4}$, which is high, attributed to no previous ANC visits and the study conducted by Alokananda et al(2005) where the incidence of IUFD was found to be $3.1 \%(1 / 32)^{3}$ which is similar to our study.

Finally, in our study, the incidence of baby admission in neonatal intensive care unit was $32.5 \%$ (13/40). The causes for higher incidence of Neonatal admissions were attributed to Neonatal sepsis and Meconium aspiration syndrome in babies. According to study conducted by Sultana et al (2009), the incidence was $26.67 \%{ }^{4}$, which was similar to our study. Alokananda et al (2005), observed the incidence of Neonatal admissions was found to be $40.6 \%(13 / 32)$, which was very high $^{3}$ attributed to high incidence abnormal cardiactocograph and meconium staining of amniotic fluid.

\section{CONCLUSION}

The cholestasis in pregnancy belongs to high risk group during pregnancy. The pharmacological therapy could improve maternal \& foetal outcome provided that variety of strategies taken during delivery with active management. The larger study is needed to establish the management protocol \& to reduce maternal and foetal morbidity \& mortality. Though this study is a small scale but it provides an important framework for management of Cholestasis in Pregnancy.

\section{REFERENCES}

1. Madazli R, Yuksel MA, Oncul M, Tuten A, Guralp Q, Aydin B. Pregnancy outcomes and prognostic factors in patients with intrahepatic cholestasis of pregnancy. J ObstetGynaecol2014; 10:1-4

2 Geenes V, Williamson C. Intrahepatic cholestasis regnancy. Worlofpd J Gastroenterol 2009; 15(17):2049-66.

3 Alokananda R, Tata Rashne J, Roshan B, Sangeeta S. Cholestasis of pregnancy.J ObstetGynecol India 2005;55(3):247-50.

4 Sultana R, Sarwar I, Fawad A, Noor S, Bashir R. Neonatal outcome in obstetric cholestasis patients at ayub teaching hospital Abbottabab. J Ayub Med Coll Abbottabad 2009; 21(4):76-8.

5 Rioseco AJ, Ivankovic MB, Manzur A, Hamed F, Kato SR, Parer JT et al. Intrahepatic cholestasis of pregnancy: a retrospective casecontrol study of perinatal outcome.Am J ObstetGynecol 1994; 170(3):890-5.

6 Gonzalez MC, Reyes H, Arrese M, Figueroa D, Lorca B, Andresen M, Segovia N, Molina C, Arce S. Intrahepatic cholestasis of pregnancy in twin pregnancies. J Hepatol 1989;9: 84-90

7 Kenyon AP, Piercy CN, Girling J, Williamson C, Tribe RM, Shennan $\mathrm{AH}$. Obstetric cholestasis, outcome with active management: a series of 70 cases. BJOG 2002; 109:282-8.

8 Germain AM, Carvajal JA, Glasinovic JC, Kato C S, Williamson C. Intrahepatic cholestasis of pregnancy: an intriguing pregnancy specific disorder. J SocGynecolinvestig 2002; 9(1):1-4.

9 Padmaja M, Bhaskar P, Gupta JK, Ramamurthy S, Chaudhuri M. A study of obstetric cholestasis. J ObstetGynecol India 2010; 60(3):225-31.

10 Mei-Ting LAM, Tsz-Kin LO, Wai-Lam LAU, Sidney TAM, Wing- 
Cheong LEUNG. Cohort Study of Suspected Obstetric Cholestasis - what have We Learned? Hong Kong J GynaecolObstet Midwifery 2014; 14(1):51-6.

11 Johnston WG, Baskett TF.Obstetric cholestasis: a 14 year review.Am J Obstet Gynecol. 1979; 133(3):299-301.

12 Reyes $\mathrm{H}$. The spectrum of liver and gastrointestinal disesase seen in cholestasis of pregnancy. GastroenterolClin North Am 1992; 21: 905-921.

13 Berg B, Helm G, Petersohn L, Tryding N. Cholestasis of pregnancy. Clinical and laboratory studies. ActaObstetGynecolScand 1986; 65: 107-113.

14 Kenyon AP, Piercy CN, Girgling J, Williamson C, Tribe RM, Shennan $\mathrm{AH}$. Pruritus may precede abnormal liver function tests in pregnant women with obstetric cholestasis: a longitudinal analysis.Bjog 2001; 108: 1190-1192.

15 Jiang ZH, Qiu ZD, Liu WW, et al. Intrahepatic cholestasis of pregnancy and its comlications. Analysis of 100 cases in Chongqing area. Chin Med J (Engl) 1986;99:957-60.

16 Fisk Nm, Storey GN. Fetal outcome in obstetric cholestasis. Br J ObstetGynaecol 1988; 95: 1137-43.

17 Bacq Y, Sapey T, Brechot MC, Pierre F, Fignon A, Dubios F. Intrahepatic cholestasis of pregnancy: A French prospective study. Hepatology 1997; 26: 358-64.

18 Alsulyman OM, Ouzounian JG, Ames-Castro M, Goodwin TM. Intrahepatic cholestasis of pregnancy: Perinatal outcome associated with expectant management (see comments). Am J ObstetGynecol 1996; 175: 957-60.

19 Mazella G, Nicola R, Francesco A, et al. Ursodeoxycholic acid administration in patients with cholestasis of pregnancy: Effects on primary bile acids in babies and mothers. Hepatology 2001; 33:504-8.

20 Berkane N, Cocheton JJ, Brehier D, et al. Ursodeoxycholic acid in intrahepatic cholestasis of pregnancy. A retrospective study of 19 cases. ActaObstetGynecolScand 2000; 79: 941-6.

21 Nicastri PI, Diaferia A, Tartagni M, Loizzi P, Fanelli M. A randomized placebo-controlled trial of ursodeoxycholic acid and S-adenosylmethionine in the treatment of intrahepatic cholestasis of pregnancy. Br J ObstetGynecol 1998; 105: 1205-7.

22 Serrano MA, Brites D, Larena MG, et al. Beneficial effect of ursodeoxycholic acid on alterations induced by cholestasis of pregnancy in bile acid transport across the human placenta. J Hepatol 1998; 28: 829-39.

23 Brites D, Rodrigues CM, Oliveria N, Cardoso M, Graca LM. Correction of maternal serum bile acid profile during ursodeoxycholic acid therapy in Cholestasis of pregnancy. J Hepatol 1998; 28: 91-8.

24 Palma J, Reyes H, Riabalta J, et al. Ursodeoxycholic acid in the treatment of cholestasis of pregnancy: A randomized, doubleblind study controlled with placebo. J Hepatol 1997; 27: 1022-8.

25 Turunen K, Sumanen M, Haukilahti RL, Kirkinen P, Mattila K.Good pregnancy outcome despite intrahepatic cholestasis. Scand J Prim Health Care2010; 28(2): 102-7.

26 Wang XD, Peng B, Yao Q, Zhang L, Ai Y, Xing AY et al. Perinatal outcomes of intrahepatic cholestasis of pregnancy: analysis of 1210 cases.Zhonghua Yi XueZaZhi 2006;86(7):446-9. 